\title{
PREPONDERANT MODALITY IN STUDENTS' ENGAGING ARGUMENTATIVE ESSAYS
}

\author{
Marwito Wihadi \\ Department of Linguistics, Faculty of Cultural Science, Universitas Padjadjaran, Indonesia \\ E-mail: marwito16001@mail.unpad.ac.id \\ Eva Tuckyta Sari Sujatna \\ Department of Linguistics, Faculty of Cultural Science, Universitas Padjadjaran, Indonesia \\ E-mail: eva.tuckyta@unpad.ac.id
}

\begin{abstract}
APA Citation: Wihadi, M., \& Sujatna, E. T. S. (2019). Preponderant modality in students' engaging argumentative essays. English Review: Journal of English Education, 8(1), 33-40. doi: 10.25134/erjee.v8i1.1930.
\end{abstract}

Received: 07-09-2019

Accepted: 15-11-2019

Published: 01-12-2019

\begin{abstract}
Expressing modality in Appraisal is cordially expected to be prevalent in argumentative writings in that writers in the Engagement System set up negotiation or alternative points of views. Three conveniently selected student-writers' hortatory argumentative essays in English in which they were courseinstructed in an accredited language institution were linguistically analyzed as to pinpoint their aptness to employ particular modality, furthermore to discuss the feasible resource factors on their employment. It was found out that they were prone to be lack of commitment as they delivered their stances, therefore attempting the readers to be engaged in an argumentative discourse to construe the meanings. Subsequently, they had difficulty in manipulating epistemic and deontic modality, owning mundane syntactic constructions and imparting limited device ranges. Therefore, applicably explicit genre-based instructions are in the need, bearing in mind the factual functions of modality in arguability of the utterances as well the resourceful linguistic features of modality.
\end{abstract}

Keywords: appraisal; engagement; modality; argumentative; essays.

\section{INTRODUCTION}

There have been a number of research on modality in which they investigated its employment and how writers used it to evaluate, adopt stances, and express attitudes on their particular value positions (Biber, 1999; McEnery \& Kifle, 2002; Kong, 2006; Qun, 2010). Writing in hortatory exposition genre, an argumentative essay, feature appraisal devices, for instance semantic realizations of modality recurrently, are worth expecting to occur numerously (Martin, 1989). Modality, a resource for presenting the degree of probability, usuality, obligation and inclination, is notified as an essential strand in appraisal (Martin, 2000). This study textanalyzing three argumentative essays was aimed at pinpointing modality employed as learners completed a seven paragraph hortatory essay in one of full-fledge language Institution. Pursuing them linguistically, it was intended to find out the scatter of its use in practice and to impart probable reasons for current combined classifications of modality (Halliday's and Palmer's) that writers/learners utilized in the reality.
Modality refers to as saying the world of realities, the speakers judge the probabilities or obligation in them (Halliday, 2000). It is considered that modality and polarity are closely related in which they are inseparable in the mood system; polarity is "the choice between positive (yes) and negative (no)", later modality has something to do more with "intermediate degrees" between the positive and negative poles, such as sometimes or maybe (Halliday, 2000). The mere distinction Halliday's modality system relative to study is Modalization: Probability and Usuality, and Modulation: Obligation and Inclination. Sensibly, modality is employed as construction of social relationship as well as recognized by communication parties as in an Appraisal: a system of interpersonal meaning to evaluate, adopt stances, and express attitude, alongside resources for amplifying and engaging with these meaning (Martin, 2000). Stances that the speakers or the writers adopt primarily rely on the modality employment. In a similar vein, it is relative to one of social language functions, namely interpersonal meta-function in which its meaning is delivered in a modality system delicately. In so-doing, 'meaning-potential' 
denoted in proposition is possibly doubted or contradicted, affirmed or denied, insisted on or accepted with reservation. As an important strand in Appraisal, in essence, modality used indicates attitudinal resources, a source of negotiation and a sign of heteroglossia.

The study of mood and modality in typological way was much fundamentally undertaken by F. R. Palmer, emphasizing the lexical forms of modality and diverse modal expression across languages (Palmer, 2007). In a broad sense, on the basis of his previous research, it is pointed out that two major classifications of modality: propositional modality, comprising Epistemic and Evidential modality and event modality, making up Deontic and Dynamic modality.

Epistemic modality deals with the writers' commitment, in divergent levels, that they put on their proposition expressed in their writing. Furthermore, it is indeed obviously relevant that they produce the language normally (Coates, 1983). It is being concerned with how they asses or assume the possibilities, in most cases, indicating their confidence as well as lack of confidence in the truth that they take for granted (Coates, 1983). Likewise, it is shown that epistemic modality is concerned with the speaker's "judgments about factual status of the preposition", whereas evidential modality reflects "the evidence" the speaker has for its "factual status" as exemplified in the up-coming examples: Perhaps this book will be useful (propositional; epistemic; judgment), and $\mathrm{He}$ is said to be extremely rich (Propositional; evidential; evidence) (Palmer, 2007). On the other hand, event modality makes up: (1) Deontic one accounting "obligation or permission" - a force from external world, and Dynamic modality delivers the "ability or willingness"- one of the inner feelings. Let's see the following utterance examples: Jhon must come in now (Deontic; external conditions) and Mary can speak French (Dynamic; internal conditions) (Palmer, 2007).

Writing an argumentative essay, a hortatory type for an instance, expects the student-writers to corroborate the importance of both language competence and rhetorical skills in expressing their arguable propositions. To contribute the quality of their argument, modalities is one of the crucial elements, apart from claim, grounds, warrants, backing and rebuttals (Toulmin et al., 1979 in McEnery \& Kifle, 2002). In fact, it is argued that negotiating views and qualifying claims at a suitable commitment grade is substantially bailed out as the writers' mastery of epistemic devices is profound (Long, 1995). Such appropriate requirements are of difficulty to be applicably attained by both native and non-native ones, though (Holmes, 1988 in McEnery \& Kifle, 2002). Despite this fact, expository, argumentative, essays should contain ample numbers of modality expressions with various semantic realization (Reilly, Zamora \& Mcgivern, 2005 in Kong, 2006).

Regarding typology of argument genres, it is proposed that there are four argument genres construing the reflection of both the writer's purposes as and his/her argument about the world: analytical exposition genre, hortatory exposition genre, analytical discussion genre and hortatory discussion genre (Coffin, 2004). Genre itself is termed as grouping texts together, representing how writers typically use language to respond to recurring situations (Hyland, 2007). In details, the term "analytical" is divergent from "hortatory" in that the earlier is an exposition persuading the readers that the thesis is adequately stated, and the latter is an exposition encouraging the readers to execute as the thesis formulated (Martin, 1985 in Promwinai, 2010). Socially "exposition "genre, additionally, is set up to aim at persuading the readers to a particular point of view where the social goal of a discussion is to hold up two or more points of view not mention to argue for one point over the others. The four arguments constitute different phases in accordance with their purposes, accordingly. Likewise, the hortatory exposition generates its own goal to impart a point of view and recommend a course action as well as comprise a typical staging: Thesis (Recommendation) + argument plus evidence + (counterargument plus evidence) + (reinforcement of thesis) + recommendation (Coffin, 2004, p. 236). Explicitly presented coming along with its elements, rhetorical structures for an argumentative essay are detailed as follow: (1) Thesis makes up (gambit), (information), proposition, (evaluation) and (marker); (2) Argument comprises marker, (restatement), claim and support; (3) Conclusion owns (marker), consolidation, (affirmation) and (close) (Hyland, 1990). In SFL tradition, thesis stage is labeled "elaboration" phase, the optional marker in the stages is termed the "preview" phase, and an obligatory marker in argument stage is referred to the "hyperclaim". Modality, appraisal theory and a particular genre of 
argument in an essay, therefore, are more or less adequately elaborated.

\section{METHOD}

The study was a descriptive-qualitative employing the researcher to interpret the real data to construe their meanings (Creswell, 2009). Essentially, this was one of three-dimensional frameworks for discourse study, namely textanalysis stemming from Critical Discourse Analysis in which language is critically viewed as a form of social practice (Fairclough, 1995; Janks, 1997). One of the core techniques to collect and analyze the data is the content analysis enabling researcher to study human behavior in a direct way, i.e. the analysis of communication forms: (argumentative) essays (Fraenkel \& Wallen, 2009). In addition, the text was analyzed to depict the employment of modality in three convenient argumentative essays-seven paragraph ones-pursued by three intermediate students in 2 a term writing course as one of their final completion level in a language course. The only three argumentative essays entitled Being a Single Parent: Gains behind Grief, Powerpoint as a Reliable Friend to Study, and The Risk on Young Children in about 3000 words completed in about 2 months in midst of High Intermediate Level Completion Course as researcher's own construction of corpora were designed so that the institutional context in non-formal settings was appropriately addressed (Paltridge, 2006). The participants, high school students aged 17 years old, had undergone writing conferences conducted outside of their class responding to meet the minimal quality standard before being presented in front of their classmates and their teacher and a language supervisor at the end of the course as one of written test fulfillment. Particularly, to employ the classifications of Modality, Halliday and Palmer's ones were, as theirs are overlapped, intentionally incorporated so as to construct four types of modal expressions displayed in the below table. However, it was also essential to be come complete with an outline the semantic realization of modality (Martin, Matthiessen \& Painter, 1997, p. 70).

Table 1. Modality classifications

\begin{tabular}{cclc}
\hline Classsification & Function & Modal Expression & Group \\
\hline Epistemic & Probability & Perhaps & E1 \\
Modality & Usuality & Usually & E2 \\
Deontic & Inclination & Can, Might & D1 \\
Modality & Obligation & Must, have to & A2 \\
\hline
\end{tabular}

The above collaborated modality classification was inspired by the study conducted by Qun (2010), still relevant to this study originating from two broad typologies promulgated by Halliday and Palmer. Then, finding out the complexity of modality structure that the writers realized was then figured by referring the exhaustive sketch. The method of analysis was initiated to focus on the body of the essays, the argument stages in which they held up hyperclaims to support writers' proposition (the $2^{\text {nd }}-6^{\text {th }}$ paragraphs) to read a number of times in order to grasp the writers' stance that was intentionally stated in and its supporting clauses; Mere sentences having clausal structures as well as contributing to maintain and develop stance were sorted to be both modality and semantic realization analysis. They were tallied as stanceenhancing clauses, thus included in total clause count differed from non-functional ones. Certainly, the text should be writer's goal- oriented and readers intended-effects so that any parts of the text, the clauses, are excluded from the linguistics analysis; they are not contributive to the central purpose (Palsmaekers, Braecke, \& Geluykens, 1998 in Qun, 2010). The selectcounted clauses were then scanned of the modality and their semantic realizations.

\section{RESULTS AND DISCUSSION}

\section{Natures of modality prevalence}

Relative with the first purpose of this study, the three essays were five-times read to grasp the nuances of writers' conveyed stances in depth. In spite of prior examined by their instructors, it was necessary that any ill-supporting clauses logically of no arguability towards the macrotheme as well as hypertheme be deliberately discarded. The encountered kinds of modality after being well comprehended, scrutinized and classified as follow. 
Table 2. The tapestry of prevalent modality

\begin{tabular}{ccc}
\hline Group & Number of Occurrences & Percentage \\
\hline E1 & 43 & $39.81 \%$ \\
E2 & 8 & $07.41 \%$ \\
D1 & 36 & $33.33 \%$ \\
D2 & 21 & $19.44 \%$ \\
\hline
\end{tabular}

E1= Epistemic Modality (EM) Probability

E2= Epistemic Modality (EM) Usuality

D1 = Deontic Modality (DM) Inclination

D2 =Deontic Modality (DM) Obligation

It was found out that the clauses containing Epistemic Modality in which the writers conveyed the probable arguments denoted by their propositions was predominant over the three other modality types $(39.81 \%)$. The writers still thought of other alternatives that the readers perceived towards their stances. In further analysis in depth, it was will asserting probability encountered preponderant, dominating to deliver the writers' viewing of possibility of 'factual status'. As a matter of fact, under the heading EM probability, will outnumbered the other modalities, such as can, it is possible, there is a possibility, certainly, etc. it covered $58.13 \%$, while can, perceived denoting possible upcoming states/conditions, was on the second place at $29.91 \%$. It was, moreover, pinpointed that the writers more or less neglected the basic function of may related to possibility (Swan, 2006).

It was an interesting fact that the altered function of will intentionally replaced can in which the writers lowered their commitment level, thus yielding less arguability of stances. Similarly, referring to the term arguability, the use of epistemic modality to report claims in an academic argument or in an argumentative essay is one of the features that have been explored in research articles written by NNES scholars, which did not achieve the conventions of required discourse communities in various fields of study or disciplines (He \& Wang, 2013; Ngula, 2017).

Will itself functions as prediction (make predictions that are not completely certain or definite) as in "Gas prices will drop soon" or Volition (express immediate decisions or intention) as in "And then I'll take you home to get it" (Beiber et al.,1999). Subsequently, may and can respectively have functional meanings to possibility (expressing agent's doubt in the truth of proposition or slight possibility) or permission (refers to present or future time when used to ask for permission or to make a polite request and giving permission to the agent) and permission (evidence of some condition that determines whether an agent is or is not permitted to do something) or possibility (express the degree to which something is possible: inanimate noun/dummy it + can + linking verb + adjective/ noun phrase; or inanimate noun + can + main verb) expressed in spoken and written modes (Beiber et al.,1999).

The L2 writers' confusion to ascertain the precise functions of (epistemic and deontic) modalities as putting forward the arguability of stances definitely occur, in congruent with their delicate comprehension in that the same modals at times are employed to express divergent functions, such as that of "probability", "possibility" and 'certainty', and of "inclination", "ability", "permission" and "obligation'. It was affirmed that Malaysian learners were disclosed to be uncertain about which modals to make use of expressing modality in their clauses, possibly easy to be figured out in the inaccurate employment of modals at the levels of semantic in particular (Khojasteh \& Rainer, 2013). Additionally, advanced Iranian EFL learners were interpreted that they were competent to use some modals due to the fact that several meanings were overly used (like "ability" meaning of can) and some of them were not really like the "possibility" meanings of can and could; as modals' interpersonal meanings were not fully grasped, they might deal with problems in social circumstances, like convincing their stances over interlocutors (Torabiardakani, Khojasteh, \& Shokrpour, 2015).

In a similar vein, referring to Metaphorical realizations of mental clause and/or attributive clause, such as I Think and I guess (explicit subjective), it is possible and it is certain (explicit objective), such clauses were rarely come across due to the fact that there were two clauses identified, that was it is possible and there is a possibility, rarely found in learner corpus (Qun, 2010). Similarly, the usage of adverbs functioning as modality of probability was much barely taped: there were only two adverbs (adjuncts) recognized, namely probably and 
certainly. It is possibly drawn into conclusion that they lacked of repertoire of semantic realizations of modality, particularly mental and attributive clauses as grammatical metaphors, i.e. expressions as well as linguistic negligence of fundamental function of may and adverbs. It was probable that one of the principles of stages in Genre-Based Course Design, genre sample analysis, was overlooked (Hyland, 2007). Pedagogically advocated, the inclusion of Devrim's intergraded model shall be taken into account. This is integrated SFL-inspired Martin and Rose's genre theory, Bernstein's sociology of education and Vygotsky's sociocultural theory, particularly focused on how students develop their Grammatical Metaphor, among other things metaphor of modality (Devrim, 2015). Afterwards, the employment of EM usuality was the least in number, just reaching $07.41 \%$, displaying a surprising fact: mere two adverbs of usuality (adjunct, mood), usually and always and methaporical realization of usuality was not of prevalence.

In addition, in line with the Deontic Modality (DM) inclination, it was the second most frequent modality activated by the writers to argue their propositions $(33.33 \%)$ in which can was the most often used one, achieving $72.22 \%$. It was obvious that adverbs (adjunct/mood) and metaphorical realizations (mental and attributive clauses) of inclination didn't prevail at all, whereas two predicators of inclination were encountered, be inclined. Interestingly, could whose tone is to negotiate proposition occurred only once. It functions as possibility, expressing the degree to which something was possible, exemplified in "That could be her or It could be anything you choose" (Beiber et al., 1999). It was identical in Chinese learners' argumentative essay in a corpus, proven it is not yet acquired in their interlanguage (Qun, 2010).

Concerning DM obligation, it was shown that it reached 19.44 where should dominated in its use $(71.43 \%)$. The other DM modality must was counted $19.05 \%$, the $0.95 \%$ of have to. The deliberate use of adjuncts, predicators (congruent realizations) and metaphorical realizations was not functionally manipulated. The word think semantically serving as probability in I think was not vividly located in the texts, even discerned to delegate the responsibility of the writers' arguments to other parties, such as some parents think, parents think and many people think, without any profound stance-enhancing references.

\section{Rationale of prevalent modality}

Critically analyzing the data findings, some perspectives were purposely referred. Modalities like will and can as elements of Grammatical Metaphors, i.e. interpersonal metaphor of modality, were frequently used in the three argumentative essays. They comprised 69 tokens over $108(63.88 \%)$. Especially referring to can, this finding was similar to previous corpus research (Qun, 2010; Torabiardakani, 2015). Its overuse was owing to two probable reasons: (1) it is attained by the learners easily that can is followed by base forms of verb; and (2) possibly, it deals with learners' ego to begin their ability to write a long enough essay in L2 (Qun, 2010). In addition, the writers, as considering their frequently used indices of stance reflected by can, imparted the commitment about a person or proposition in the appraisal system referred; hence, they can align or misalign the stance taker with another person or proposition (Biber et al., 1999). In other words, taking a stance (writers' arguments) via metaphors of modality is one of the essential things people do with words ( $\mathrm{Du}$ Bois, 2007 in Gales, 2015).

In line with the stance, the writers were unlikely get aware of various repertoire of transmitting the authority of the authors' as well as demanding the credibility, and engagement, through its sub-category, namely entertainment '- a sub category of engagement in appraisal system - can and will', is the required instrument entailing readers. Then, it prompts co-agents of the discourse in an interactive, in this case, argumentative genre. Related to linguistic metafunction, interpersonally stance is the foci of language aspect, realized through strewn linguistics markers, modality for an instance, in a text - an essay (Martin \& Rose, 2003).

Pertaining Bahktinian's (1986) sense, every "utterance is a link in a very complexly organized chain of other utterance," hence the writer simply attempted to be engaged with the presence of the readers (speakers) by anticipating their alternative point of views. No utterances are classified into monolossic or heteroglossic, accordingly. However, the heterogloss use of can and will denoted the possibility of being dialogically expansive or entertain in that a range of potential opinions are possibly available regardless of how strong they are committed to particular viewpoints (Martin \& White, 2005).

Feasibly, the excessive employment of modality can and will relative to the insights of the polyfunctionality of modal markers, 
seemingly geared by the complex communicative strategies of the speaker/writer and their coparticipants. As for speakers/writers, it is observed that in verbal dialogsm via the composed text, where participants are attempting to achieve simultaneously the goals of (a) saying something on the topic under discussion; (b) being sensitive to the face-needs of the various addressees; (c) qualifying assertions to avoid total commitment to a point of view which they may want to withdraw from; (d) qualifying assertions to encourage the flow of discussion; (e) creating cohesive text, then it does not seem feasible to conclude "this form expresses $\mathrm{x}$ and that form expresses y" (Coates, 1983; Voloshinov, 1995). The writers took the above aspects of dialogism into consideration, retrieving their surviving level of modality metaphor at hand.

Obviously encountered in the argumentative essays, it was feasible for them to have difficulty in expressing the semantic realizations of modality in further than finites (can, could, might) as the other parts of realizations (adjunct(mood)/adverbs), predicators, mental clauses and attributive clauses were barely localized in the texts. The prevalent fact possibly rested to explicit teaching on such modality as stated that learners should have the knowledge of "what is socially and culturally appropriate in terms of the writer roles, audience expectations, rhetorical and stylistic conventions, and situational or contextual features of written" (Reid, 1990). In other words, it is argued that it is supposed to be promulgated in the course design (Hyland, 2007; Kong, 2006). According to Devrim (2015), an integrated model shall be pedagogically cultivated as a rhetorically oriented approach to teaching Grammatical Metaphors like that of modality. Likewise, an integrated model positions the metaphor of modality within English as a second/foreign language (ESL/EFL) contexts and concentrates on the text types argumentative genre, for example, that diverse cohorts that occurred in the study were required to compose.

Juxtaposing the modal expression, it was notified that the frequent appearance of Deontic Modality was a bit higher than that of epistemic modality. This was then explained by Sweetser's cognitive perspective confirming that deontic modality is the root of modality whose semantic extension is epistemic one; hence, deontic modality acquisition and exercise is easier than epistemic modality one. Moreover, learners who are exposed to particular language will build cognitive systems that can be activated any time when a stimulus is provided. This issue relates to the fundamental notion in second language acquisition: automaticity-linguistic knowledge and restructuring-internalized representations as a result of new learning (Gass \& Selinker, 2001). In other words, exposure to the various metaphor of modality as an input in a specific writing genre ought to be ample, then followed up by meaningful metafunctions so as to pursue the application of certain linguistic features, turning into intake activated later on given situations. Such interaction, therefore, indeed promotes the language acquisition substantially so that language aspects are linguistically and socially developed. The more recurrent interaction that entails cognitive and social domains, the better the language performance of the use of modality and the nearer to second language acquisition are. The discussed research findings shall be, subsequently, wrapped up to infer.

\section{CONCLUSION}

Critically analyzing the discourse on the three argumentative-hortatory-essays, it is succinctly drawn a conclusion that in general deontic modality is slightly higher in frequency than epistemic modality. The monotonous use of finite modals is overused and scattered in the texts, highlighting the fact that other semantic realizations of modality are overlooked, or much probably not yet adequately exposed so as to get acquired by the learners. Furthermore, the solid insights of metaphor of modality are not well ingrained, leading the confusion employment in context. Dialogism sense corroborates the low level of arguable stances, while considering participants' potential viewpoints. On the other side, finite modals may and might are less favored to be employed, voicing writers' realization of probability and inclination. Exposing further functions and realizations of modality in a specific genre meeting discourse community features and conventions, then exercising them in the real contexts is in the need of applications in explicit genre-based teaching in the integrated model on-line and tutor-assisted to promote metaphor of modality.

\section{ACKNOWLEDGEMENT}

I thank LPDP (Lembaga Pengelola Dana Pendidikan) for financial support and Prof. Dr. Eva Tuckyta Sari Sujatna, M.Hum. for academic supervision. 
ENGLISH REVIEW: Journal of English Education

Volume 8, Issue 1, December 2019

\section{REFERENCES}

Biber, D., Johanssson, S., Leech, G., Conrad, S., \& Finegan, E. (1999). Longman grammar of spoken and written English. London: Longman.

Coates, J. (1983). Semantics of the modal auxiliaries. London: Croom Helm.

Coffin, C. (2004). Arguing about how the world is or how the world should be: The role of arguments in IELTS tests. Journal of English for Academic Purposes, 3(3), 229-246.

Creswell, J. (2009). Research design: Qualitative, quantitative, and mixed-methods approach. London: SAGE Publication, Inc.

Devrim, D. Y. (2015). Grammatical metaphor: What do we mean? What exactly are we researching? Functional Linguistics, 2(3), 1-15.

Fairclough, N. (1995). Critical discourse analysis. London: Longman.

Fraenkel, J. R., \& Wallen, N. E. (2009). How to design and evaluate research in education $\left(7^{\text {th }} e d\right)$. New York: McGraw-Hill Higher Education.

Gales, T. (2015). Identifying interpersonal stance in threatening discourse: An appraisal analysis. Discourse Studies, 13(1), 27-46. doi: $10.1177 / 146 / 445610387735$.

Gass, S. M., \& Selinker, L. (2001). Second language acquisition: An introductory course (2nd ed.). New Jersey: Lawrence Erlbaum Associates, Inc.

Halliday, M. A. K. (2000). An introduction to functional grammar. London: Edward Arnold.

He, Y., \& Wang, H. (2013). A corpus-based study of epistemic modality markers in Chinese research articles. Chinese Lexical Semantics, 7717, 199208.

Hyland, K. (1990). A genre description of the argumentative essay. RELC Journal, 21(1), 6678 .

Hyland, K. (2007). Genre and second language writing. Michigan: The University of Michigan Press.

Janks, H. (1997). Critical discourse analysis as a research tool. Accessed on May 22 ${ }^{\text {nd }}, 2017$ from www.uv.es/gimenes/Recursor/criticaldiscourse.p df.

Khojasteh, L., \& Reinders, H. (2013). How textbooks (and learners) get it wrong: A corpus study of modal auxiliary verbs. Applied Research on English Language, 2(1) 33-44.

Kong, C. K. M. (2006). Modality in appraisal in students' essay: A study of the effect of genrebased instruction. Accessed on April 2 $2^{\text {nd }}, 2017$ from http://hdl.handle.net/10497/495.

Long, E. (1995). Negotiating competing voices to construct claims and evidence: Urban America teenagers rivalling anti-drug literature. In P.
p-ISSN 2301-7554, e-ISSN 2541-3643

https://journal.uniku.ac.id/index.php/ERJEE

Costello \& S. Mitchel (Eds), Competing and consensual voices: The theory and practice of argument (pp. 35-49). Bristol: Multilingual Matters.

Martin, J. R. (1989). Factual writing: Exploring and challenging social reality $\left(2^{\text {nd }} e d.\right)$. Oxford: Oxford University Press.

Martin, J. R. (2000). Beyond exchange: Appraisal system in English. In S. Hunston \& G. Thompson (Eds), Evaluation in text: Authorial stance and the construction of discourse (pp. 142-175). Oxford: Oxford University Press.

Martin, J. R., \& Rose, D. (2003). Working with discourse: Meaning beyond the clause. New York: Continuum.

Martin, J. R., \& White, P. R. R. (2005). The language of evaluation. New York: Palgrave Macmillan.

Martin, J. R., Matthiessen, C. M. I. M., \& Painter, C. (1997). Working with functional grammar. New York: Arnold.

McEnery, T., \& Kifle, N. A. (2002). Epistemic modality in argumentative essays of second language writers. Accessed on June 21 $1^{\text {st }}, 2017$ from http: www.reserachgate.net/publication/3.pdf.

Ngula, R. S. (2017). Epistemic modal verbs in research articles written by Ghanaian and international scholars: A corpus-based study of three disciplines. Brno Studies in English, 43(2), 1-24. doi:10.5817/BSE2017-2-1.

Palmer, F. R. (2007). Mood and modality. New York: World Book Publishing Company.

Paltridge, B. (2006). Discourse analysis: An introduction. London: Continuum.

Promwinai, P. (2010). The demand of argumentative essay writing: Experiences of Thai tertiary students. Accessed on July, 20 ${ }^{\text {th }}, 2016$ from http://www.ro.uow.edu.au/theses/3298.

Qun, Z. (2010). Modality and generic features in Chinese EFL writings. Chinese Journal of Applied Linguistics, 33(5), 40-51.

Reid, J. (1990). Responding to different topic types: A quantitative analysis from contrastive perspective. In B. Krol (Eds), Second language writing: Research insights for the classroom. Cambridge: Cambridge University Press.

Swan, M. (2006). Practical English usage. Oxford: Oxford United Press.

Torabiardakani, N., Khojasteh, L., \& Shokrpour, N. (2015). Modal auxiliaries and their semantic functions used by advanced EFL learners. Acta Didactica Napocensia, 8(2), 51-60.

Voloshinov, V. N. (1995). Marxism and the philosophy of the language. Translated by L. Matejka \& I. R. Titunik, Cambridge, MA: Harvard University Press. 
Marwito Wihadi \& Eva Tuckyta Sari Sujatna

Preponderant modality in students' engaging argumentative essays 